\title{
Effects of Pearl Grass Extract Capsules on Osteoarthritis Subject
}

\author{
Nita Sari Wijaya ${ }^{1}$, Katrin Basah², Anton Bahtiar ${ }^{1, *}$
}

Nita Sari Wijaya', Katrin Basah', Anton Bahtiar ${ }^{1, *}$

'Department of Pharmacology and Toxicology, Faculty of Pharmacy, Universitas Indonesia, Kampus UI Depok, 16424, INDONESIA.

${ }^{2}$ Department of Phytochemistry, Faculty of Pharmacy, Universitas Indonesia, Kampus UI Depok 16424, INDONESIA.

\section{Correspondence}

\section{Anton Bahtiar}

Department of Pharmacology and

Toxicology, Faculty of Pharmacy,

Universitas Indonesia, Kampus UI Depok, 16424, INDONESIA.

E-mail: anton.bahtiar@farmasi.ui.ac.id History

- Submission Date: 18-11-2019:

- Review completed: 12-12-2019;

- Accepted Date: 06-01-2020

DOI : 10.5530/pj.2020.12.48

Article Available online

http://www.phcogj.com/v12/i2

\section{Copyright}

(C) 2020 Phcogi.Com. This is an openaccess article distributed under the terms of the Creative Commons Attribution 4.0 International license.

\begin{abstract}
Pearl grass extract, a standardized bioactive polar extract of the herbs of Hedyotis corymbosa, is preclinically proven to have an activity to osteoarthritis and rheumatoid arthritis properties in an animal model. The current clinical study has evaluated the efficacy and safety of Pearl grass extract of osteoarthritis subjects.

This research was a pilot study of osteoarthritis subjects using Parallel double-blind study design. Subjects have normal renal and liver function, above 50 years of age, and has a sign and symptoms of osteoarthritis included in the study. In the treatment, Pearl grass capsules were given as one capsule once daily for eight weeks, throughout the study, the weekly assessment to evaluate the adverse event.

Thirty subjects of mean age $55.90 \pm 3.7$ years were evaluable. Pearl grass extract capsules did not change renal and liver function in 56 days treatment. Pearl grass capsule markedly reduced the consumption of analgesic drug compared with placebo groups. Pearl grass capsules also decreased pain scale better compare with placebo.

Key words: Clinical efficacy; Pearl grass extract capsules; Quercetin; WOMAC scale; VAS scale.
\end{abstract}

\section{INTRODUCTION}

Osteoarthritis defined by the American College of Rheumatology as a heterogeneous condition of a group of symptoms and signs associated with the integration of bone cartilage, in addition to its relationship with the changes that occur in the bone at the joint boundary. ${ }^{1}$ Osteoarthritis $(\mathrm{OA})$ is a form of arthritis most often found in society, are chronic, have a major impact on public health issues. Osteoarthritis can occur with different etiology but result in abnormalities biologist, morphological and clinical same output. ${ }^{2}$

The prevalence after age 65 years of about $60 \%$ in men and $70 \%$ in women. Osteoarthritis is multifactorial etiology of the inflammatory factors, metabolic, and mechanical causes. The number of environmental risk factors such as obesity, trauma work and may cause various pathways that cause disease. The disease process is not just about the weak joints but also the entire joint, including subchondral bone, ligaments, capsule and synovial tissue and periarticular connective tissue. ${ }^{3,4}$ In later stages of cartilage damage characterized by the fibrillation, fissures, and ulceration in the joint surface. It should understand that the $\mathrm{OA}$ is a disease with a slow progression, with unknown etiology. There are several risk factors for OA, namely: obesity, muscle weakness, excessive physical activity or less, previous trauma, decreased proprioceptive function, heredity suffering from $\mathrm{OA}$ and mechanical factors. Age over 65 years, only $50 \%$ provide radiological features correspond Osteoarthritis. Although just $10 \%$ of men and $18 \%$ women among them who showed clinical symptoms of $\mathrm{OA}$, and approximately $10 \%$ had a disability due to OA her, it can be understood that older adults have higher possibility to developing
OA. Along with increasing life expectancy, according to the WHO in 2025 the old population in Indonesia will be increased by $414 \%$ compared to $1990 .^{2}$

The principle of treatment is to control pain adequately, improve function and decrease disability. Acetaminophen is the drug most often used as a symptomatic treatment of mild to moderate osteoarthritis. NSAIDs (Non-steroidal Anti-Inflammatory Drugs) is more effective in cases of moderate to severe, but increase the risk of serious gastrointestinal. Inhibitors of COX 2 (cyclooxygenase 2) Latest (coxibs) more effective as traditional NSAIDs and affect the digestive safer. Other components such as chondroitin sulfate, glucosamine sulfate have a symptomatic effect of slower and less efficient than NSAIDs. ${ }^{5}$

Pearl grass (Hedyotis corymbosa L.Lamk) is one of the plants that contain compounds that are flavonoids, kaempferol, iridoids, stigmasterol, triterpenoids, Ursolic acid, hentriacontane. ${ }^{6}$ Pearl grass also contains oleanolic acid, p-cumaric acid, glycosides, alizarin, and bonding anthragalol. Some properties which have efficacy as an anti-inflammatory, diuretic, antipyretic, antitoxin, enhancing phagocytosis of white blood cell and hormonal immunity. ${ }^{7}$ In studies using animals pearl grass extract which contains active compounds, one of which is a flavonoid, has efficacy decrease in the number of leukocytes which works by inhibiting the release of proinflammatory cytokines that influence the number of leukocytes. ${ }^{8}$ Effect of preventive and curative in $70 \%$ ethanol extract of pearl grass (Hedyotis corymbosa L.Lamk) on the immune system in a mouse model of osteoarthritis induced sodium iodoacetate; Effect of preventive administration of $70 \%$ ethanol extract pearl grass (Hedyotis corymbosa (L.) Lamk.) to changes in rat models of proteoglycans in the joints of osteoarthritis. $^{8}$ 
Clinical effectiveness of pearl grass extracts as anti-osteoarthritis have not studied, so in this study, we evaluated pearl grass extract effect on osteoarthritis subject.

\section{METHODOLOGY}

\section{Extract preparation}

Simplicia Pearl grass (H. corymbosa L. (Lamk)) was extracted by maceration using $70 \%$ ethanol for $3 \times 24 \mathrm{hrs}$ then concentrated by rotary evaporator at a temperature of $40-50^{\circ} \mathrm{C} .^{8}$ The pearl grass extract then added by maltodextrin as diluent before inserting it into the capsule shell.

\section{Extract characterization}

Samples of $1 \mathrm{~g}$ of pearl grass extract capsules diluted by methanol, then bring volume to $100 \mathrm{ppm}$ as final concentration. Then subject to LCMS/ MS using gradient eluent of Eluent A and B. Eluent A contained 0.1 Formic acid and Eluent B contained asetonitrile and 0.1 formic acid. The pressure 18.000 Psi.

\section{Clinical trial}

A parallel, double-blind, randomized design as stated in the procedure below.

\section{Research design}

This research undertook a 2-group, parallel, double-blind, randomized clinical trial (RCT).

\section{Ethics statement}

The protocol and consent form for this study approved by the institutional ethics committee of Universitas Indonesia, Jakarta. Appointments scheduled for an eligible patient, where the risks and benefits of their possible participation reviewed by subject. The subject read and signed the informed consent form before the study.

\section{Study participants}

Between July 2016 and December 2016, we enrolled healthy nonsmoking people aged 50 to 70 years.

We excluded patients who have one or more the conditions as follow: any herbal medicine supplements, consumption of $\geq 2$ alcoholic drinks per day. The subject who have allergy or intolerance to herbal, hormone replacement therapy (HRT) or hormonal contraception in the preceding six months before the pre-randomization visit. Women with systolic blood pressure $\geq 160 \mathrm{mmHg}$, diastolic blood pressure $\geq 100$ $\mathrm{mmHg}$, or treated with antihypertensive medications excluded.

\section{Recruitment and randomization}

Subjects recruited from the general population of Tangerang City through Primary care group center in Posbindu Kecubung, in the region of primary care Tajur, Ciledug. Potential study participants in the study contacted the study coordinator who explained the research project to them and verified inclusion and exclusion criteria. We do an interview, and physical examination based on inclusion and exclusion criteria and then asked them to read the informed consent form and discussing with their family then sign the inform consent. We had randomization process by separated into two groups, placebo and pearl grass extract capsules. Every group got diclofenac sodium for emergency relief while then feel much pain. After their signing the inform consent, we begin to take laboratory test for a screening test. Then one week later we accompany participants to have another laboratory examination and roentgen examination (AP/lateral positions), after the result out, we began the treatment and every week we were following up patients and do review for every two weeks.

\section{Allocating participants to trial groups}

At the randomization visit, participants randomly assigned to either Placebo or Pearl grass extract capsules. The randomization schedule prepared at Primary care group center.

\section{Intervention}

Daily Pearl grass extract capsule $\cong 1.52 \mathrm{mg}$ of quercetin. Study participants consumed $1 \times 1$ capsules per day for eight weeks. Liver and kidney function assessed at 0 and eight weeks.

\section{Baseline}

A short questionnaire which documented social and demographic characteristics, alcohol consumption, and medication, was completed by participants. Anthropometric data were measured according to a standard protocol. Food habits during the last month were estimated by validated questionnaire.

\section{Follow-up visits}

Participants should be returned to our clinical research facility to follow-up visits every week from weeks 0 until weeks 8 , and we had evaluated every two weeks. Blood samples were taken at the beginning of the trial, before treatment, and after treatment. Blood pressure was measured at every visit.

\section{Evaluation of side-effects}

Digestive and other symptoms (dyspepsia, diarrhea, paresthesia, and headache) were documented by a questionnaire administered at randomization and each study visit.

\section{RESULTS AND DISCUSSION}

\section{Identification of the extract}

We have identified the content of the Pearl grass extract capsules using LC-MS/MS. The result was shown in Figure 1.

We then evaluated by MS and found five component that have high concentration in the capsule as shown in Figure 1 and Table 1. In Table 1 , it appears that the capsules of pearl grass extract tested were detected containing quercetin, quercetin is a flavonoid compound that plays a role in the anti-inflammatory process by inhibiting the release of proinflammatory cytokines such as Tumor Necrosis Factor and Interleukin 1. However the highest compound in the capsule that appears on the examination of LC -MS / MS is aurantiamide acetate. Aurantiamide acetate is a compound which is reported to be able to inhibit the effects of Tumor Necrosis Factor $\alpha$ (TNF- $\alpha$ ) and interleukin (IL-2) which play a role in the process of inflammation, so that the inflammatory process is inhibited, in addition, aurantiamide acetate also acts as an antineuroinflammation by means of weakens the release of inducible NO synthase (iNOS), cyclooxygenase-2 (COX-2), and other cytokine products so that the patient experiences a decrease in pain. ${ }^{9}$

\section{Characteristic of subjects}

Table 2 showed that Both groups have similar characteristic on the age, systole and Diastole pressure, Body weight and the height. Therefore Pearl grass extract capsules group and placebo can be concluded that population is similar.

\section{Determination of renal and liver functions to evaluate the safety of samples}

Renal function and liver function were determined to evaluate the safety of this capsule. We identified AST (Aspartate Aminotransaminase) and ALT (Alanine transaminase) as an indicator of damage to cells in the 


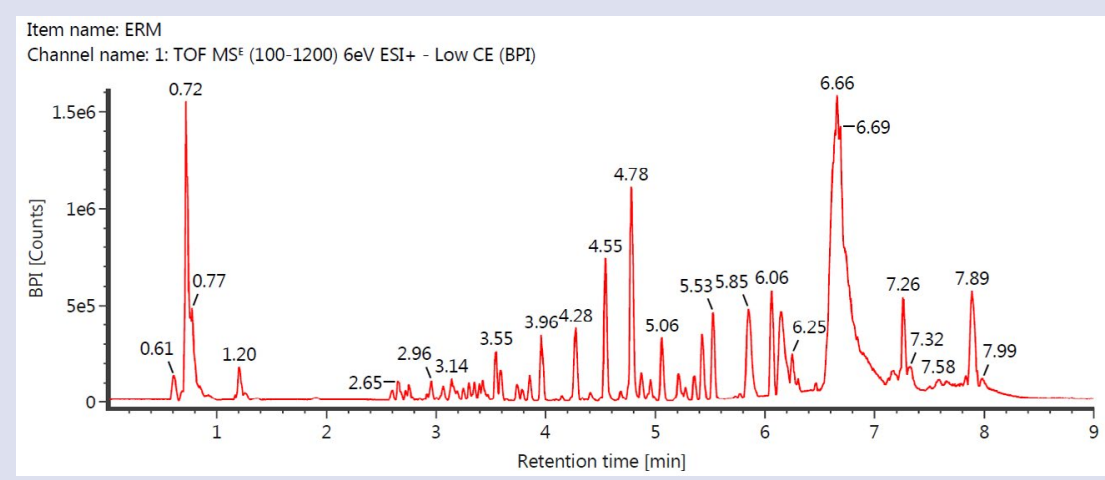

Figure 1: Chromatograms of the pearls grass extract capsules.

Table 1: Identification of components by MS.

\begin{tabular}{cccccccc}
\hline & Component name & Identification status & Observed $\mathbf{m} / \mathbf{z}$ & Observed RT $(\mathrm{min})$ & Detector counts & Response & Adducts \\
\hline 1 & Aurantiamide acetate & Identified & 445.2121 & 5.36 & 245337 & 92953 & $+\mathrm{H},+\mathrm{Na}$ \\
2 & Bufotalinin & Identified & 415.2113 & 5.43 & 363391 & 188180 & $+\mathrm{H},+\mathrm{Na}$ \\
3 & Isomaltose & Identified & 365.1049 & 0.73 & 803311 & 658521 & $+\mathrm{Na},+\mathrm{H}$ \\
4 & Picroside I & Identified & 515.1523 & 4.28 & 173527 & 129365 & $+\mathrm{Na},+\mathrm{H}$ \\
5 & Quercetin & Identified & 303.0495 & 3.19 & 50819 & 43547 & $+\mathrm{H}$ \\
\hline
\end{tabular}

Table 2: Characteristic of subjects.

\begin{tabular}{ccc}
\hline Description & Placebo Group & Pearl grass extract Group \\
\hline Age (Year) & $56.53 \pm 4.36$ & $59.65 \pm 7.11$ \\
Sistole $(\mathrm{mmHg})$ & $118,57 \pm 15,74$ & $125.00 \pm 17.01$ \\
Diastole $(\mathrm{mmHg})$ & $70,71 \pm 13,67$ & $81.50 \pm 8,75$ \\
Body weight $(\mathrm{Kg})$ & $56.75 \pm 6.49$ & $61.9 \pm 9.51$ \\
Body Height $(\mathrm{Cm})$ & $150.62 \pm 5.70$ & $153.5 \pm 0.07$ \\
BMI & $27,02 \pm 3,04$ & $29,4 \pm 4,88$ \\
\hline
\end{tabular}

liver. Cell degeneration and cell damage showed the high number of these enzymes. After took a pearl grass extract capsules for 56 days, it showed AST and ALT of the subjects were not changed.

We also evaluate kidney function by determined Urea $\mathrm{N}$, urea, and creatinine. One of the functions of the kidneys is to excrete waste products such as urea, uric acid, creatinine, and other toxic substances. Kidney function may impair as a result of many factors, such as obstruction. Examination of BUN, urea, and creatinine can be used as an indicator to determine the occurrence of disorders of the kidneys. In the severe renal impairment levels of blood urea, nitrogen and creatinine increased. BUN levels normal range from 13.9 to $28.3 \mathrm{mg} /$ $\mathrm{dL}$ and the creatinine levels normal range is 0.30 to 1.00 . Table 3 showed that was not changed in Ureum and creatinine.

In elderly, they have a high risk for hypertension, so then we evaluated blood pressure of the subjects, and the result was shown in Table 4. There are no effects of treatment on blood pressure as shown in Table 3.

Osteoarthritis (OA) is a "wear and tear" disease, they are leading to loss of cartilage, but recently, people found that subchondral bone may have a substantial role in the OA processes. ${ }^{10}$ Recent studies show a lot of review about inflammatory that was happened in osteoarthritis processes associated with pain that occur on a patient with osteoarthritis are also connected to inflammatory mediator which produce by bone, cartilage, and synovium. ${ }^{10}$ Inflammatory processes such as synovitis, innate immunity as a trigger of local inflammation in $\mathrm{OA}$, direct mechanical signaling, and low-grade systemic inflammation in OA was the role of inflammatory processes associated with pain in OA patients. ${ }^{10}$ The ensuing cellular response culminates in activation of specific transcription factors, with nuclearfactor $\kappa \mathrm{B}(\mathrm{NF}-\kappa \mathrm{B})$ playing a prominent role. Chemokine and cytokine which is responsible to synovitis process on synovium are, IL-1, IL6 , TNF, and common- $\gamma$ chain family of cytokines (including IL2, IL-15, and IL-21). Inflammatory processes can inhibit by using nonsteroidal anti-inflammatory agents (NSAIDs), such as ibuprofen, diclofenac sodium, piroxicam, etc. The mechanism by which NSAIDs exert their anti-inflammatory and analgesic effects is via inhibition of the prostaglandin-generating enzyme, cyclooxygenase (COX), as a reduction of prostaglandin level. It also works on gastric ulceration, renal insufficiency, improvement of the risk of cardiovascular diseases and prolonged bleeding time occurred as a side effect of NSAIDs.

Otherwise, herbal treatment such as pearl grass (Hedyotis corymbosa L.Lamk) has been known as one of the herbs with anti-inflammatory effect. ${ }^{11}$ Pearl grass (Hedyotis corymbosa L.Lamk) is one of the plants that contain flavonoids, kaempferol, iridoids, stigmasterol, triterpenoids, Ursolic acid, hentriacontane. ${ }^{6}$ They also contained oleanolic acid, p-cummaric acid, glycosides, alizarin, and bonding antragalol. Some properties which have efficacy as an anti-inflammatory, diuretic, antipyretic, antitoxin, enhancing phagocytosis of white blood cell and hormonal immunity. In studies using animals pearl grass extract which contains active compounds, one of which is a flavonoid, has efficacy decrease in the number of leukocytes which works by inhibiting the release of proinflammatory cytokines that influence the number of leukocytes. ${ }^{8}$

In the other hands, Hedyotis corymbosa hasn't been evaluated in a clinical trial before, so then we evaluated between Pearl Grass Extract and placebo into capsules, and also we compared Pearl Grass Extracts capsules and Placebo who gave diclofenac sodium as an emergency treatment for the pain. We have evaluated enchantment of the disease by using WOMAC score and VAS score as pain scale. WOMAC score (Western Ontario and McMaster's Universities Osteoarthritis Index) 
was the most frequently used for assessing pain in a patient with OA. The WOMAC is a self-assessment for patients with OA on the knee and hip. WOMAC consist 24 items where divided into three dimensions. Namely pain, function, and stiffness with 5, 2, and 17 questions, respectively. WOMAC is rated by the Likert scale on 0 to 4 of an ordinal scale of, low scores indicating low levels of symptoms or physical disability. Each subscale is summated to a maximum score of 20,8 , and 68 for the value of pain, function, and stiffness, respectively. This measurement was developed to evaluate clinically significant, patient-relevant changes in health status as a result of treatment intervention. High scores on the WOMAC indicated worse pain, stiffness, and functional limitations. ${ }^{12}$ Figure 2 was described the percentage of total WOMAC score between Placebo and Pearl Grass Extract in OA patients.

As shown in Figure 2, placebo groups have different from pearl grass extract group (PGECC), on placebo group, on weeks 4th participants have WOMAC score higher than weeks 2 nd, and gradually decreased until weeks 8th, but still higher than PGEC group. Otherwise, on PGEC group from weeks 0 until weeks 8 th, continuously showed decreasing WOMAC score, means PGEC group has therapeutic effect better than placebo groups. We also compared each item of WOMAC score between groups, as seen in Figure 3 and Figure 4.

On the other hands, we also examine the level of pain by VAS scores. VAS score consists of a straight line defining extreme limits of pain start from 'no pain at all' to 'pain as bad as it could be. The subject was asked to mark they pain level on that line between the two endpoints. The distance between 'no pain at all' and the mark of the pain of them then defines as subject's pain..$^{13}$ As shown in Figure 5, Subjects in PGECC group had lower VAS score than placebo groups. On first two weeks, there's no difference between two group on pain. 2 weeks later, the pain gradually increased until two weeks then on Placebo group, but in PGECC group the pain decreases progressively until the end of the experiment. The similar result also is shown on the also demonstrated in diclofenac consumptions on Figure 6.

In contrast, diclofenac consumption between two groups, as emergency relief while participants feel pain cannot reduce by using only placebo or PGEC. The placebo group, pretending to less consume for the beginning of the treatment. While the end of the procedure, in the placebo group, consuming diclofenac sodium as pain reliever much more higher than PGECC group. It opposed with WOMAC score and VAS score above, the decreasing pain of participants on placebo group because of they're using diclofenac sodium as their painkiller. Besides, participants on PGEC extracts, no significantly decreasing consumptions from the beginning of the treatment till the end of the procedure.

As seen in Figure 7, We have also compared the X-ray interpretation between Placebo and PGEC groups both right and left sides of OA patients. Using Kellgreen-Lawrence radiographic criteria, there's grade 0 - grade 4 osteoarthritis. We categorized it into three categories, worsening, same and better. If there's improvement grade of osteoarthritis from the lower grade to the higher grade, it means worst, if there's no improvement, that means same, and if there's improvement grade of osteoarthritis from higher become lower grade, that means

Table 3: The effects of Pearl grass extract capsules on liver and renal function during experimental time.

\begin{tabular}{ccccc}
\hline & \multicolumn{2}{c}{ Placebo Group } & \multicolumn{2}{c}{ Pearl grass extract Group } \\
\hline & Before & After & Before & After \\
AST (U/L) & $19,57 \pm 3,87$ & $17.2 \pm 1.48$ & $24,29 \pm 12,54$ & $26 \pm 14.24$ \\
ALT (U/L) & $18,14 \pm 6,15$ & $12.4 \pm 2.07$ & $22,71 \pm 8,81$ & $20.17 \pm 6.21$ \\
Ureum (mg/dL) & $26,27 \pm 5,03$ & $27.82 \pm 3.7$ & $29,57 \pm 8,21$ & $21.2 \pm 6.78$ \\
Creatinine (mg/dL) & $0,88 \pm 0,21$ & $0.98 \pm 0.21$ & $0,78 \pm 0,20$ & $0.82 \pm 0.22$ \\
LED & $31,71 \pm 21,03$ & $45.75 \pm 15.84$ & $36 \pm 8,31$ & $32.17 \pm 5.42$ \\
\hline
\end{tabular}

Table 4: The effects of pearl grass extract capsules on cardiovascular parameter of $O A$ subjects.

\begin{tabular}{ccccc}
\hline & \multicolumn{2}{c}{ Placebo Group } & \multicolumn{2}{c}{ Pearl grass extract capsule Group } \\
\hline & Before & After & Before & After \\
Systole $(\mathrm{mmHg})$ & $118,57 \pm 15,74$ & $116 \pm 13,41$ & $111,25 \pm 11,57$ & $115 \pm 18.71$ \\
Diastole $(\mathrm{mmHg})$ & $80.00 \pm 7.07$ & $79.00 \pm 7.38$ & $84.44 \pm 8.82$ & $78.00 \pm 9.19$ \\
\hline
\end{tabular}

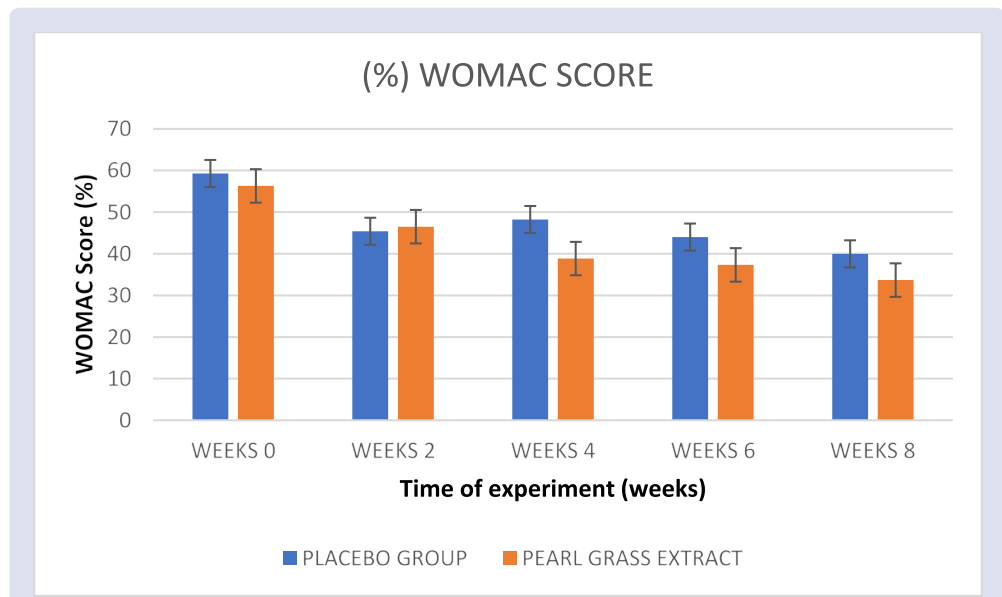

Figure 2: Percentage of total WOMAC score in Placebo and pearl grass extract capsules group in OA patients. 


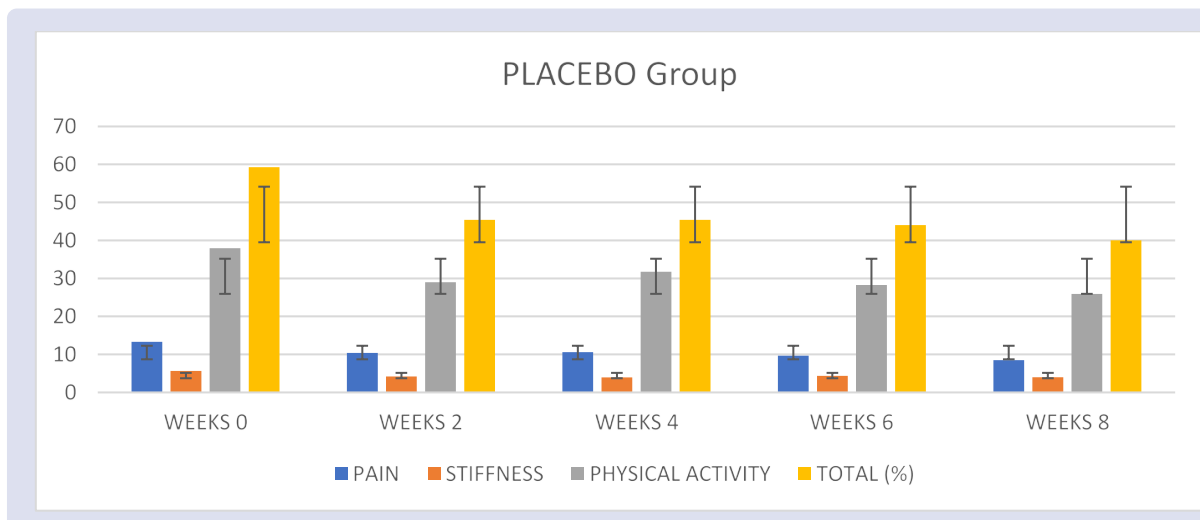

Figure 3: Parameters of WOMAC score in placebo group in OA patients.
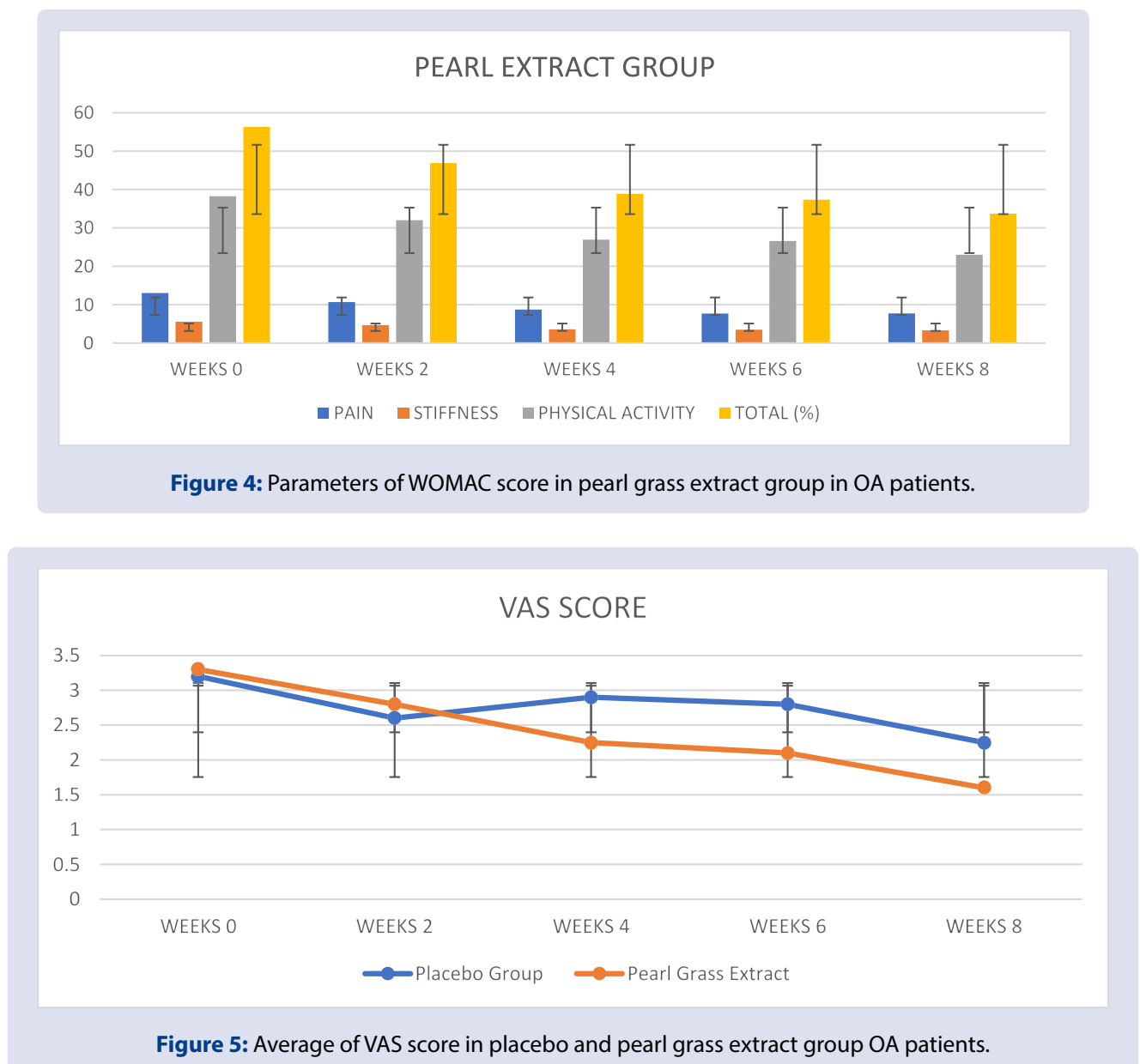

better. As shown in bar chart using Crosstab, on placebo groups, both in the right side and left the side, dominantly have been same and worst, only one person in placebo groups in right side has improved from higher to lower grade. PGEC group on the right side and left side showing better results than placebo groups, although predominantly without changes in both two groups.

We had examined correlations between those variables, from WOMAC score, VAS score, Diclofenac consumptions and ImageJ assessment for radiology results with SPSS 20.0 Version, using Spearman correlations two-tailed that observed on the table above, with coefficient correlations $\mathrm{p}<0.05$. ImageJ was used to measure the differentiation between space narrowing of the synovial space which showing on participants X-ray. The test of correlation shown that on placebo groups, there's strength correlation between WOMAC and VAS score $(\mathrm{p}<0.05)$. This is means that pain perception was decreased by participants which confirmed by VAS score, similar with WOMAC score, but, the average of consumption diclofenac sodium not correlated with WOMAC score or VAS score ( $\mathrm{p}>0.05)$, and also Both WOMAC score or VAS score are not related with radiology examination by using ImageJ.

During this experiment, there's adverse effect that occurs from weeks 0 to weeks 8 , mostly both in placebo and PGEC group feel paresthesia, while they're consuming Pearl grass capsules, besides participants also felt dyspepsia that also can occur because of using analgetic. Others feel energizing, feel easy to sleep, diarrhea, and allergy occur after analgetics consumptions. So after occurring allergy, we have dropped out the patients. Another adverse event can see in Table 5. 


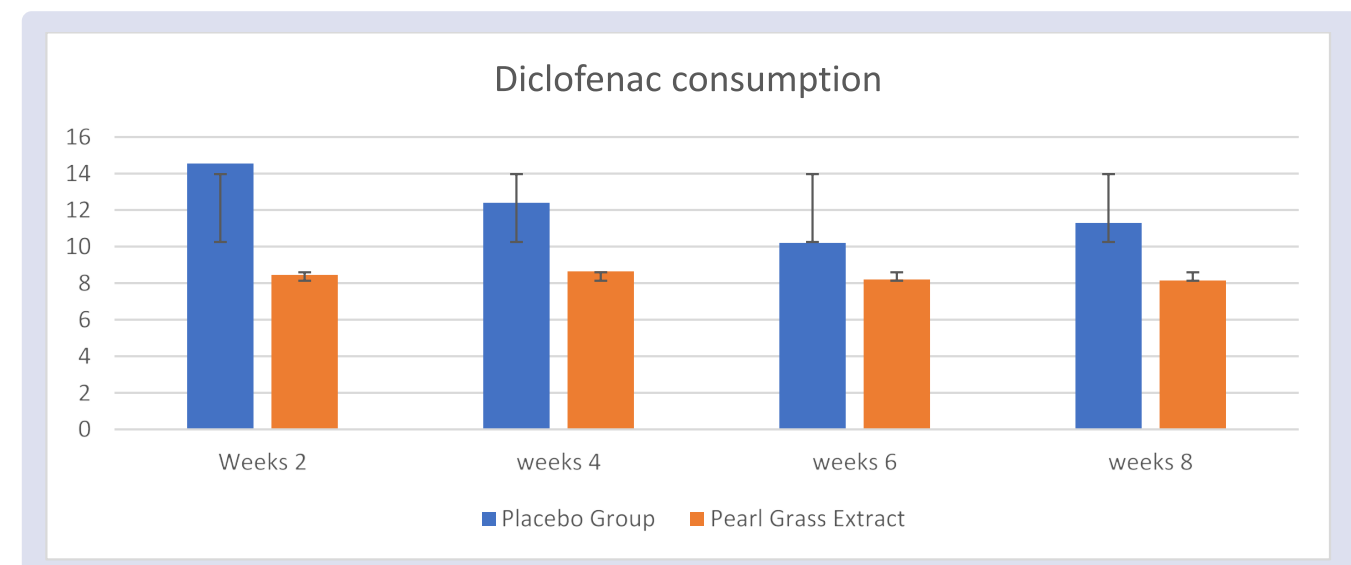

Figure 6. Diclofenac Consumption between Placebo and Pearl Grass Extract Capsule Group in OA Patients
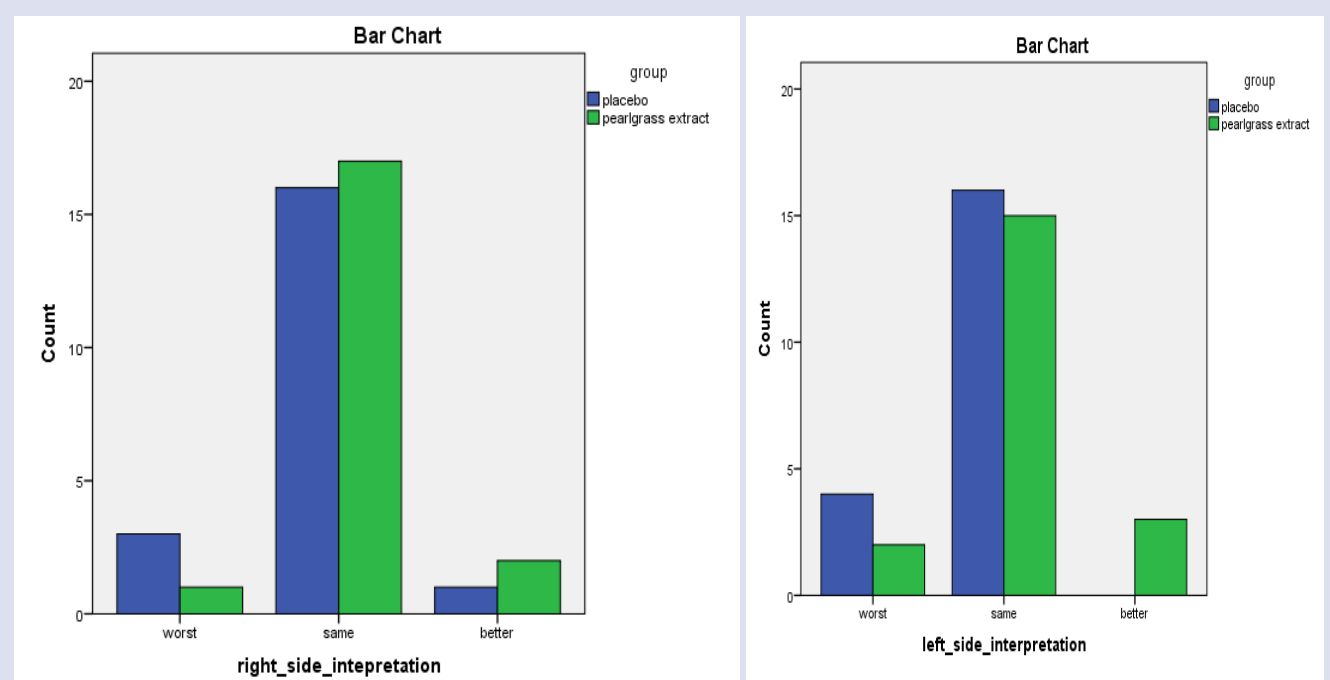

Figure 7. X-ray Interpretation Placebo Group and PGEC Groups in OA Patients

Table 5: Adverse event between placebo groups and pearl grass extract groups in OA patients.

\begin{tabular}{ccc}
\hline Adverse Event & Placebo & $\begin{array}{c}\text { Pearl Grass } \\
\text { Extract Capsules }\end{array}$ \\
\hline Insomnia & $4.54 \%$ & $2.27 \%$ \\
Feel easy to sleep & $2.27 \%$ & $4.54 \%$ \\
Allergy & $4.54 \%$ & $0 \%$ \\
Headache & $4.54 \%$ & $0 \%$ \\
Myalgia & $6.81 \%$ & $2.27 \%$ \\
Diarrhea & $0 \%$ & $2.27 \%$ \\
RTI (Respiratory Tract Infection) & $4.54 \%$ & $6.81 \%$ \\
Parasthesia & $45.45 \%$ & $45.45 \%$ \\
Increased appetite & $9.09 \%$ & $22.72 \%$ \\
Decreased Appetite & $6.81 \%$ & $4.54 \%$ \\
Increased Dyspepsia & $6.81 \%$ & $2.27 \%$ \\
Decreased Dyspepsia & $0 \%$ & $4.54 \%$ \\
Energizing & $15.90 \%$ & $20.45 \%$ \\
Polydipsia & $0 \%$ & $6.18 \%$ \\
\hline
\end{tabular}




\section{CONCLUSION}

After all the treatment from the beginning until the end, pearl grass extract capsules was safe consumed by a human. We also evaluate the effectiveness of the PGEC capsules by comparing it with placebo and using diclofenac sodium as emergency relief for pain. Parameters we have been used was WOMAC score, VAS score, and X-ray assessment and compare each other, every group. As the results, tend towards reduced analgesic drug consumption, and the correlation between parameters showed the there's correlation only between WOMAC, VAS score, and Diclofenac consumptions, but not changing on radiology itself.

\section{CONFLICT OF INTEREST}

The authors declare that there is no conflict of interest regarding the publication of this paper.

\section{ACKNOWLEDGEMENT}

This research was supported by The Ministry of Research, Technology and Higher education research Grant 2015-2016 second years.

\section{REFERENCES}

1. Wu CW, Morrell MR, Heinze E, Concoff AL, Wollaston SJ, Arnold EL, et al. Validation of American college of rheumatology classification criteria for knee osteoarthritis using arthroscopically defined cartilage damage scores. Semin Arthritis Rheum. 2005;35(3):197-201.

2. Tochigi $Y$, Ogawa M, Kakihana M, Masuda $Y$, Ozeki S. Etiology of ankle osteoarthritis in an Asian population. Foot Ankle Surg. 2017;23:113-4.
3. Lawrence CR, East B, Rashid A, Tytherleigh-Strong GM. The prevalence of osteoarthritis of the sternoclavicular joint on computed tomography. J Shoulder Elb Surg. 2017;26(1):e18-22.

4. Veronese N, Stubbs B, Noale M, Solmi M, Luchini C, Smith TO, et al. Adherence to a Mediterranean diet is associated with lower prevalence of osteoarthritis: Data from the osteoarthritis initiative. Clin Nutr. 2017;36(6):1609-14.

5. Sarzi-Puttini P, Cimmino MA, Scarpa R, Caporali R, Parazzini F, Zaninelli A, et al Osteoarthritis: An Overview of the Disease and Its Treatment Strategies. Semin Arthritis Rheum. 2005;35(1, Supplement 1):1-10.

6. Kim S-J, Chung W-S, Kim S-S, Ko S-G, Um J-Y. Antiinflammatory effect of oldenlandia diffusa and its constituent, hentriacontane, through suppression of caspase-1 activation in mouse peritoneal macrophages. Phyther Res. $2011 ; 25(10): 1537-46$

7. Chimkode R, Patil MB, Jalalpure S, Pasha TY, Sarkar S. A study of hepatoprotective activity of hedyotis corymbosa. linn, in albino rats. Anc Sci Life. 2009;28(4):32-5.

8. Bahtiar A, Sari FA, Audina M, Datunsolang NLC, Arsianti A. Ethanolic extracts of hedyotis corymbosa L. Improves monosodium iodoacetate-induce osteoarthritis in rat. Asian J Pharm Clin Res. 2017;10(3).

9. Yoon CS, Kim DC, Lee DS, Kim KS, KoW, Sohn JH, et al. Anti-neuroinflammatory effect of aurantiamide acetate from the marine fungus Aspergillus sp. SF-5921: Inhibition of NF-kB and MAPK pathways in lipopolysaccharide-induced mouse BV2 microglial cells. Int Immunopharmacol. 2014;23(2):568-74.

10. Berenbaum F. Osteoarthritis as an inflammatory disease (osteoarthritis is not osteoarthrosis!). Osteoarthr Cartil. 2013;21(1):16-21.

11. Ahmad R, Ali AM, Israf DA, Ismail NH, Shaari K, Lajis NH. Antioxidant, radical-scavenging, anti-inflammatory, cytotoxic and antibacterial activities of methanolic extracts of some Hedyotis species. Life Sci. 2005;76(17):1953-64.

12. Gandek B. Measurement properties of the western ontario and mcmaster universities osteoarthritis index: A systematic review. Arthritis Care Res (Hoboken). 2015;67(2):216-29.

13. Haefeli M, Elfering A. Pain assessment. Eur Spine J. 2006;S17-24.

\section{GRAPHICAL ABSTRACT}

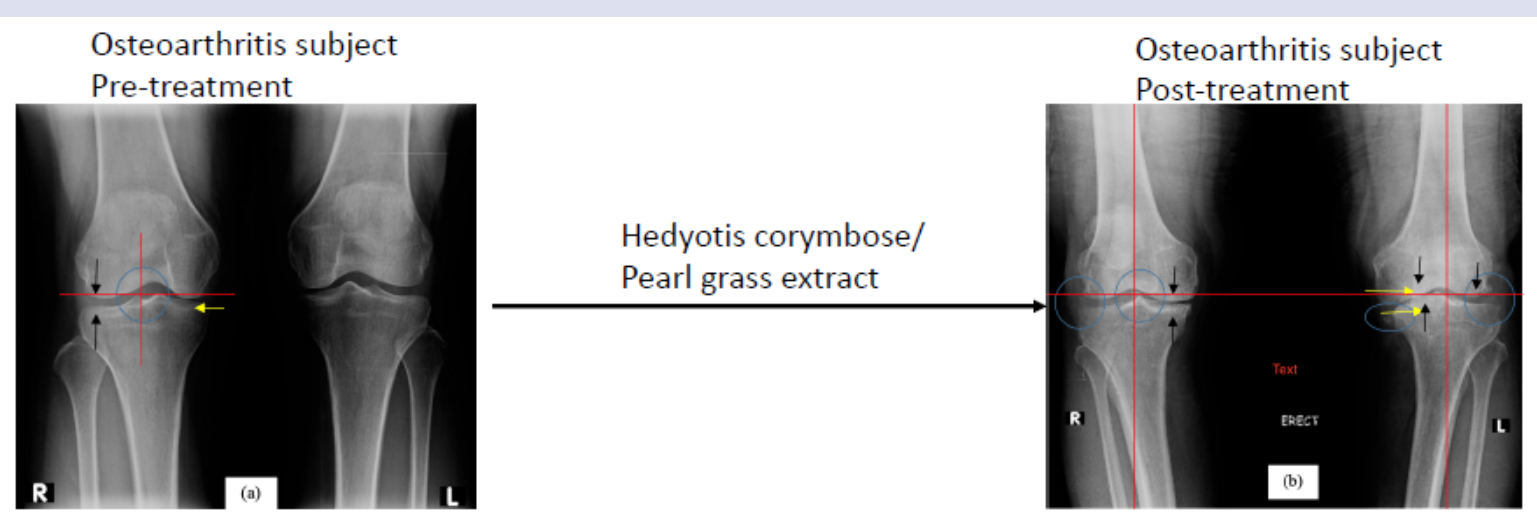

\section{ABOUT AUTHORS}

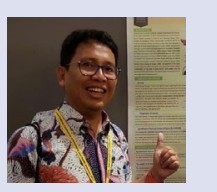

Anton Bahtiar obtained his Ph. D. degree in 2010 from Nara Institute of Science and Technology, Japan. Currently, $\mathrm{He}$ is lecturer and researcher at faculty of pharmacy, University of Indonesia since 1998. He is also a head of Pharmacology and Toxicology Laboratory. His research projects are focus on Herbal medicine, and tried to solve the mechanism of action of herbal medicine, especially for osteoporosis and menopouse.

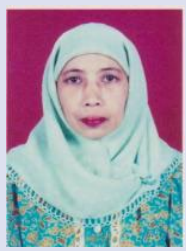

Katrin Basah obtained her Ph.D degree from Bandung Institute of Technology, Bandung-Indonesia. She was lecturer and researcher on Faculty of Pharmacy Universitas Indonesia. 
Nita Sari Wijaya obtained her master degree in 2018 from Faculty of Pharmacy Universitas Indonesia, Depok-Indonesia.

Cite this article: Wijaya NS, Basah K, Bahtiar A. Effects of Pearl Grass Extract Capsules on Osteoarthritis Subject. Pharmacog J. 2020;12(2):303-10. 